\title{
O Estatuto do Objeto na Psicanálise Lacaniana: uma Comparação com o Objeto da Ciência
}

\author{
Rosane Zétola Lustoza ${ }^{1}$ \\ Universidade Estadual de Londrina
}

\begin{abstract}
RESUMO - O artigo visa pensar a especificidade do conceito lacaniano de objeto $a$, distinguindo-o do objeto tal como é construído pelas ciências experimentais. Ao mesmo tempo, seguindo as indicações de Lacan de que o $a$ seria uma metáfora do objeto de conhecimento, busca-se o sentido em que o objeto da psicanálise e o objeto da ciência poderiam ser aproximados. A conclusão é que seu traço em comum é a propriedade de invariabilidade. O caráter de invariabilidade do $a$ será considerado em uma dupla acepção: como causa de desejo e como mais-gozar, na tentativa de encontrar uma dimensão em que ambas se articulem.
\end{abstract}

Palavras-chave: objeto $a$; objeto científico; causa de desejo; mais-gozar.

\section{The Object Statute in Lacanian Psychoanalysis: A Comparison with Science Object}

\begin{abstract}
The article aims to think the specificity of lacanian concept of object $a$, distinguishing it from the object such as it is constructed by experimental sciences. At the same time, following Lacan indications that the $a$ would be a metaphor of the knowledge object, one pursues in what sense the psychoanalysis object and the science object could be approached. The conclusion is their trace in common would be the invariability. The feature of invariability of the $a$ will be considered in a double meaning: as a cause of desire and as surplus of enjoyment, in the attempt to find a dimension where both are articulated
\end{abstract}

Key words: object $a$; scientific object; cause of desire; surplus of enjoyment.

Este artigo pretende pensar o estatuto do objeto em psicanálise a partir da elaboração por Jacques Lacan do conceito de objeto $a$. O interesse desse tema se justifica uma vez que, enquanto nas ciências ditas experimentais o objeto de investigação deve ser sempre algo capaz de dar lugar a algum tipo de observação (senão de fato, pelo menos de direito), na psicanálise, o objeto $a$ constituiria algo cujas características não poderiam ser isoladas na realidade material. O que suscita a questão: em que sentido poderíamos afirmar que o $a$ é um objeto?

Considerando que tanto a ciência quanto a psicanálise utilizam o termo objeto, embora o façam em sentidos diferentes, acredito ser necessário um esforço para pensar o que distingue e o que aproxima ambos os conceitos. A discussão pode então servir para desfazer mal-entendidos gerados por uma homonímia entre os termos. Depois de investigar que características fazem do $a$ um objeto, abordarei esse conceito em uma dupla vertente: como causa de desejo e como mais-gozar. A seguir será demonstrado como se articulam essas duas dimensões, utilizando para isso o conceito que opera uma mediação entre ambas: o de fantasma. A fim de limitar o alcance do trabalho e, dessa forma, aprofundar o entendimento dos conceitos, outras definições do objeto $a$ (tais como as de resto, agente do discurso analítico, vazio, etc.) não foram aqui trabalhadas, considerando-o, portanto, exclusivamente como causa de desejo ou mais-gozar.

\section{O Objeto na Ciência e na Psicanálise}

O termo objeto é retirado da relação de conhecimento, fazendo a psicanálise um uso metafórico do mesmo. Com a

1 Endereço: Rua Goiás, 1777, apt. 307, Londrina, PR, Brasil 86020-410. E-mail:rosanelustoza@yahoo.com.br finalidade de dar um sentido a essa noção, recorreremos às elaborações da epistemologia acerca do estatuto do objeto na atividade científica, para só então procurarmos fornecer uma interpretação do sentido de sua utilização pela psicanálise. É importante advertir que, por uma razão de método, circunscrevi essas reflexões epistemológicas ao estatuto do objeto nas ciências físicas e químicas. O objeto científico não é uma realidade existindo em si e por si, sendo antes resultado de uma construção pela ciência. $\mathrm{O}$ objeto não é algo cuja existência possa ser postulada previamente ao processo de conhecimento, mas sim o resultado de uma longa elaboração. Ele não constitui um dado que se impõe independentemente da atividade científica, como se fosse seu ponto de partida; mas antes o ponto ao qual a ciência chega ao final de um trabalhoso percurso.

Nesse esforço de construção do objeto, o itinerário seguido pelo cientista deverá proceder por eliminação progressiva dos elementos subjetivos. Expliquemos melhor. Suponhamos que um dado se apresente para nós. Se, variando as condições de observação, novos dados surgirem, isso significa que estamos diante de meras aparências, cuja existência depende da posição de observação assumida por nós. Tais dados, gerados diretamente pelas modificações da posição do observador, receberiam por isso mesmo o estatuto de subjetivos.

Inversamente, o índice de objetividade de um conhecimento consistirá precisamente na independência de certo resultado em relação à variação das condições de observação. O cientista está seguro de ter alcançado a objetividade quando consegue atingir consistentemente um mesmo resultado, independentemente dos meios utilizados para estabelecê-lo. Como diz Blanché, 1948:

Se o melhor índice de objetividade de um conhecimento reside, para o cientista, na convergência dos 
resultados obtidos por métodos diferentes, é porque esta concordância mesma, quando não se pode racionalmente atribuí-la ao acaso, testemunha que os resultados não dependem dos procedimentos múltiplos e diversos pelos quais foi atingido (p. 133).

A constância em relação aos pontos de vista será o sinal, permitindo ao cientista identificar o objeto. O objeto só poderá ser reconhecido pelo cientista mediante uma constante deformação das condições iniciais da experiência, que serão incessantemente transformadas a fim de se atingir um invariante, algo que permanecerá o mesmo ao longo de todas essas transformações. É interessante notar que se chega ao invariante, não abrindo mão de qualquer perspectiva de observação, mas sim procurando o que permanece inalterável no decurso das variações de posição. Em síntese, embora a multiplicação das condições de observação dê origem a uma série de dados distintos entre si, é possível isolar um invariante, algo que não é afetado pelas transformações, e que será chamado de realidade objetiva.

A atividade científica moderna criou então a possibilidade de se traçar uma linha de separação entre o que é objetivo e o que é subjetivo: "o que caracteriza essencialmente a física tal como nós a conhecemos é a separação definitiva que ela estabelece entre a realidade verdadeira e as aparências 'subjetivas" (Gurwitsch, 1935, p. 167). O subjetivo passará a ser descartado pela ciência como o domínio do que é variável, do que permanece irredutivelmente prisioneiro de uma posição específica qualquer. O subjetivo será o terreno daquilo que se encontra vinculado diretamente a particularidades de todo tipo, desde a constituição biológica de nossa espécie (nossas sensações, por exemplo) até os valores do grupo social:

À luz das ciências físicas, todo o aspecto fenomenal do mundo: as qualidades consideradas secundárias, os caracteres de valor de todas as espécies, os momentos teleológicos que ele parece conter, etc., não constituem nada de real; com esses fatos está-se em presença de uma contribuição que se deve à subjetividade humana, e que o homem, graças à sua constituição psico-fisiológica, projeta sobre um universo que é de uma outra natureza (Gurwitsch, 1935, p. 167).

Esta região que a ciência recortou como subjetiva será doravante identificada como sendo o mundo psíquico.

O percurso que fizemos pela ciência ajuda-nos a olhar sob outra luz a investigação freudiana, levando-nos a resgatar a originalidade da sua pergunta. Pois, sendo o subjetivo o que será descartado pela ciência como o domínio daquilo que é variável, atrelado a particularidades de todo o tipo, a vitalidade da obra freudiana reside no seguinte questionamento: poderíamos isolar algo de invariável no próprio território do subjetivo? Ou, para usar termos freudianos, existiria algo de real no psíquico?

Se o $a$ deve ser denominado o objeto da psicanálise é precisamente por constituir o invariante psíquico que estamos procurando. Isso não o transforma em hipótese alguma em objeto de ciência - o próprio Lacan admite estar fazendo um uso metafórico de um termo importado do domínio do conhecimento: “... designar este pequeno a pelo termo de objeto é fazer um uso metafórico da palavra, tomando-a de empréstimo à relação sujeito - objeto, de onde o termo objeto se constitui" (Lacan, 1962-63/2004, pp. 102-103). No entanto, como qualquer metáfora, isola um traço pertinente aos dois termos em questão, que é, no caso em exame, a invariância. Vejamos a seguir em que medida é legítima essa aproximação, examinando o objeto $a$ nas duas funções que desempenha: como causa de desejo e como mais-gozar.

\section{O Objeto $a$ como Causa de Desejo}

Quando o $a$ exerce a função de causa de desejo, onde podemos localizar a invariância? À primeira vista a objetalidade parece difícil de identificar no registro do desejo sexual, uma vez que este constitui precisamente um impulso que não se satisfaz inteiramente com nenhum objeto da realidade. O desejo se define como uma falta que, por que impossível de ser preenchida, não pode se contentar com qualquer objeto empírico. Por estar submetido a um regime de incessante variação, o registro do desejo parece ser o mais avesso a qualquer tentativa de encontrar um invariante.

Ora, a resposta que procuramos já se encontra na descrição: pois, o que essa incessante movimentação do desejo permite circunscrever como invariável é precisamente que nenhum objeto pode obturar a falta que o constitui. Isso só pode acontecer porque o desejo é falta de nada. Se o desejo jamais pode ser inteiramente satisfeito por qualquer objeto empírico, é porque o único ponto que não varia em todos os seus deslizamentos é sua ligação a algo que é nada. Lacan fará equivaler esse nada à insistência de algo irredutível ao significante, resto que causa o desejo. O retorno permanente disso que é heterogêneo ao significante, sendo o que precisamente autoriza a recortá-lo como objeto. No lugar desse objeto que o deslocamento significante permite delimitar como ausente, Lacan colocará uma letra: $a$.

Apresentando-se a princípio como o que é rebelde à ordem simbólica, o objeto deflagrará, justamente por isso, um esforço no sentido de sua reabsorção. $\mathrm{O} a$ acionará o desejo na medida em que este constituirá um impulso visando capturálo para o interior do sistema. Esforço infinito, já que, tal como o paradoxo de Zenão, quanto mais o sujeito se aproximar do objeto, mais este se furtará, restando sempre um excedente irredutível ao significante.

\section{O Objeto a como Mais-gozar}

Segundo a leitura que Jacques Lacan faz da obra freudiana, o desejo corresponde a uma dimensão em que o sujeito se encontra fundamentalmente insatisfeito. Por sua vez, a satisfação pulsional diz respeito a um registro em que o sujeito se encontra sempre satisfeito. O objeto $a$ exerce então um duplo papel em Lacan: ele será ao mesmo tempo causa de desejo e objeto da pulsão. Como apreender essa segunda função do objeto $a$ ? E, principalmente, como circunscrever seu caráter invariante, que concederia a ele o status de objeto? Tentemos responder à questão examinando o conceito freudiano de pulsão.

A famosa tese freudiana em Três ensaios sobre a teoria da sexualidade é a de que o objeto da pulsão é contingente (Freud, 1905/1996). Embora a exigência pulsional incida sobre um objeto qualquer, a essa contingência inicial segue-se 
uma fixação (Fixierung). Por que o sujeito fica fixado a uma certa representação? Poderiam ser dadas múltiplas razões para justificar a fixação de um sujeito a uma certa posição. De fato, sua sujeição a um certo referencial simbólico é sempre suscetível de ser explicada por várias causas. Mas o que Freud paulatinamente descobriu é que, por mais longe que vá a interpretação, resta sempre um umbigo, um ponto de não-saber (Freud, 1900/1996). Em outras palavras, é possível fornecer infinitas justificativas para o sujeito ter aderido a uma certa posição, contudo nenhuma delas constitui uma condição suficiente. Isso significa que, em última instância, o investimento libidinal em uma certa posição não pode se amparar em qualquer razão suficiente, já que ele consiste num ato primeiro, cego e não fundamentado, uma escolha inconsciente que retroativamente $o$ sujeito tentará explicar buscando suas causas. De certa maneira, a exigência pulsional não é justificada por nenhuma razão, antes as razões que oferecemos para justificar uma certa posição nossa (por exemplo, os motivos que levam alguém a crer na existência de Deus) só são convincentes porque nós já acreditamos nela (tais motivos só serão acatados pelo crente porque este já tem fé!). A exigência pulsional não é condicionada pelas razões que damos para um determinado ato, ela é antes condição que torna possíveis o ato e suas razões.

Quando dizemos que a exigência pulsional não respeita condições, isso não significa de modo algum que tal investimento seja irreversível. É claro que uma fixação pode "cair", o sujeito deixando de se importar com algo que anteriormente era valioso para ele. Mas o que se quer sublinhar aqui é que está fora de nosso alcance controlar esses investimentos, o momento em que vamos nos ligar ou nos desligar de uma representação. Daí vêm as abundantes queixas que escutamos na clínica, em que um paciente, por exemplo, lamenta ter permanecido tempo demais ao lado de alguém que, entretanto, há muito já tinha deixado de preencher suas “condições de amor"... Esses são os momentos mais propícios para proporcionar ao sujeito um encontro com um apego que aparece como sem sentido, desproporcional, até mesmo irracional...

A Fixierung traduz a invariância que vínhamos procurando no campo do gozo. Essa invariância pode ser isolada pelo aspecto "indestrutível" de um investimento avesso a qualquer interpretação, que torna impossível formular as condições que fariam com que o sujeito se ligasse ou se desligasse do Outro. É como se o sujeito encontrasse momentaneamente um "absoluto", algo que ele não consegue relativizar ou reverter por qualquer manobra sua. Por isso que, parafraseando Leibniz, o objeto da pulsão é o que permanece o mesmo em todos os mundos possíveis.

\section{O Objeto $a$ em sua Dupla Função: Causa de Desejo e Mais-gozar}

Para articular as duas vertentes do objeto $a$, apelaremos doravante para a noção lacaniana de fantasma² . Uma das funções do fantasma é oferecer as coordenadas, permitindo dar certa orientação para o desejo. Uma vez que os investimentos libidinais podem se dirigir virtualmente a qualquer

2 Para consultar uma obra de referência sobre o conceito lacaniano de fantasma é recomendável recorrer ao estudo de Slavoj Zizek intitulado The plague of fantasies (Zizek, 1999). objeto, o fantasma permitirá fornecer uma direção a essa libido em princípio cega.

O fantasma desempenhará o papel de oferecer um esquema, permitindo ao sujeito realizar uma seleção entre os objetos existentes na realidade empírica. Alguns objetos empíricos estarão automaticamente descartados, por estarem fora da janela do fantasma, do enquadramento graças ao qual um objeto pode aparecer como desejável. Outros ingressam no interior do quadro, e é somente a um desses que o sujeito poderá se ligar. Desse modo, o fantasma atua como um mediador entre o desejo e os objetos positivamente dados na realidade externa.

$\mathrm{O}$ fantasma não se limita a oferecer um objeto-meta para o desejo. Até porque a meta é apenas um chamariz, não é ela que causa o desejo. O que causa o desejo será não a meta, mas tudo aquilo que permitir o relançamento do desejo. E o desejo será relançado precisamente por um resíduo que resiste à significantização. O desejo desliza metonimicamente graças ao objeto $a$, que coincide com o limite da simbolização. O fantasma inaugurará então um campo no interior do qual o sujeito irá continuamente desencontrar-se com o objeto $a$, abrindo um caminho onde ele vai mais se perder do que se encontrar.

Analisei como o fantasma se relaciona com o desejo; resta saber qual sua relação com a pulsão. O fantasma constitui uma cena que representa a relação sexual como realizada. Essa propriedade está presente em qualquer fantasma, a de constituir uma promessa de gozo. Não de um gozo qualquer, mas de um gozo completo, absoluto, um gozo que nos faria plenos. Tal satisfação poderia ser atribuída pelo sujeito tanto ao passado quanto ao futuro.

Embora Lacan nos lembre que esse gozo que nos faria felizes e completos está interditado para o sujeito da linguagem, é preciso esclarecer que a inexistência de uma satisfação total não significa que não haja satisfação alguma. Há um gozo que vem em suplência à ausência da relação sexual. Em relação a esse gozo, o fantasma exercerá o papel de tela encobridora. Desse modo, se a função mais evidente desempenhada pelo fantasma é a de prometer um gozo pleno, não devemos nos cegar para sua outra função, que a primeira trabalha precisamente para mascarar. Pois, ao mesmo tempo em que faz supor a existência de uma satisfação total, o fantasma tem por efeito ocultar o real da satisfação pulsional (mais-gozar).

A função de velamento do fantasma pode ser detectada nas falas mais cotidianas, quando nós, por exemplo, permanecemos em uma situação de sofrimento intolerável em nome da relação sexual, suposta tanto ao passado ("tenho a esperança que nosso namoro volte a ser tão bom quanto era no início") quanto ao futuro ("um dia ele vai se transformar no que eu quero"). O fantasma, às vezes, sofre um abalo e é então que, para o sujeito, se desvela um gozo até então desconhecido, manifestando-se como um apego insensato que não pode ser justificado razoavelmente por nenhum motivo. É o que os analisandos vêm testemunhar com falas do tipo "não consigo me desligar dessa pessoa, ela mostrou não ser nada do que eu queria, mas mesmo assim eu não consigo deixar de querê-la...”. Nesse investimento, que não pode ser explicado por nada, podemos isolar a exigência pulsional.

Eis que emerge a dimensão da pulsão, de uma exigência que não pode ser justificada por qualquer razão, pois ela se fixou ao que há em ti mais do que tu, à alteridade no seio 
do Outro, o objeto $a$. Por isso os melhores exemplos permitindo circunscrever a heterogeneidade do $a$ em relação ao significante são justamente aquelas situações em que nos deparamos com um apego que excede qualquer justificativa: quando o objeto, por exemplo, mostra ser o contrário do que dizíamos querer e, ainda assim, nós persistimos aderidos a um estúpido mais-gozar.

\section{Referências}

Blanché, R. (1948). La science physique et la realité - réalisme, positivisme, mathématisme. Paris: PUF.

Freud, S. (1996). A Interpretação dos Sonhos. Em Edição Standard das Obras completas de Sigmund Freud, vol. IV/V. Rio de Janeiro: Imago Editora. (Trabalho original publicado em 1900)

Freud, S. (1905/1996). Três ensaios sobre a teoria da sexualidade. Em Edição Standard das Obras completas de Sigmund Freud, vol. VII. Rio de Janeiro, Imago Editora.. (Trabalho original publicado em 1905)

Gurwitsch, A. (1935). Développement historique de la gestaltpsychologie. Thalès, 2, . 167-176.

Lacan, J. (2004). Le séminaire: livre 10. L'angoisse. (1962-1963) Paris: Seuil.

Zizek, S. (1997). The plague of fantasies. New York: Verso.

Recebido em 28.03.2007

Primeira decisão editorial em 15.06.2007

Versão final em 21.06.2007

Aceito em 26.07.2007 